\title{
Testicular cancer and intellectual disability
}

Annie J Sasco, MD, MPH, MS, DrPH ${ }^{1,2}$, Roland Ah-Song, MD ${ }^{1}$, Motoi Nishi, $\mathrm{MD}, \mathrm{PhD}^{3}$, Stéphane Culine, $\mathrm{MD}^{4}$, Marie-Odile Réthoré, $\mathrm{MD}^{5}$ and Daniel Satgé, $\mathrm{MD}, \mathrm{PhD}^{6}$

${ }^{1}$ Team of Epidemiology for Cancer Prevention, Inserm CRE U 897, Bordeaux cedex, France, ${ }^{2}$ Université Victor Segalen Bordeaux 2, Case 11, Bordeaux cedex, France, ${ }^{3}$ Department of Fundamental Health Sciences, Health Sciences University of Hokkaido, Hokkaido, Japan, ${ }^{4}$ Service d'Urologie, Hopital Henri Mondor, Créteil, France, 'Institut Jérôme Lejeune, Paris, France and ${ }^{6}$ Laboratoire d'Anatomie pathologique, Centre hospitalier de Tulle, Tulle, France

Abstract: The frequency of testicular cancer in men with intellectual disabilities is not precisely known, with the exception of some genetic conditions such as Down syndrome, where it has increased. Objective: To review systematically the literature through Pubmed with a particular focus on epidemiological studies of testicular cancer in persons with intellectual disability. Method: Literature review. Results: Testicular cancer was more frequent in subjects with intellectual disability than in the general population. Yet the occurrence depended on the specific genetic condition. The study of the association with not genetically determined intellectual disabilities remains to be done. Conclusion: Clinicians in charge of men with intellectual disability should be aware of the association with testicular cancer.

Keywords: Testicular cancer, Down syndrome, cryptorchidism, intellectual disability

Correspondence: Annie J Sasco, MD, DrPH, Team leader, Epidemiology for Cancer Prevention, Inserm CRE U 897, Case 11, Université Victor Segalen Bordeaux é, 146 rue Leo Saignat, 33076 Bordeaux, France. Tel: ++ 3355757 45 12; Fax: ++ 335562400 81; E-mail: Annie.Sasco@isped.u-bordeaux2.fr

Submitted: April 25, 2008. Revised: May 22, 2008. Accepted: June 02, 2008

\section{INTRODUCTION}

Incidence of testicular cancer greatly increased over the last decades in the Western world. Its epidemiology indicates a role for exposure to hormonal factors, as well as endocrine disruptors. Evidence suggests that men with Down syndrome experience a higher frequency of testicular cancer than the general population, which warrant increased surveillance (1). Occurrence in other causes of intellectual disability (ID) is less known. One common feature includes the fact that cancer is often diagnosed at an advanced stage in these patients $(2,3)$. Delay in diagnosis and consequently in treatment may be explained by poor communication between patient, caretakers and medical team (4), familial or institutional context, including conditions of medical follow-up, or more often, by a combination of all these different factors. All these 
situations bear in common a misapprehension of cancer in people with intellectual disability.

Late diagnosis in such patients result in further suffering for themselves their families, as well as an increased burden for the medical team, because of the treatment required to provide them with the best chances for recovery. Adequate oncologic management is necessary to increase survival, bearing in mind that cancer in general may be as common among the intellectually disabled as in the general population $(5,6)$, but with a particular tumor type distribution (7). We would like to draw attention to the frequency of testicular cancer among the intellectually-disabled and underline the need for particular care in routine examination of the external genitalia in such patients. Our argumentation is based on the published epidemiological and clinical data.

\section{EPIDEMIOLOGICAL STUDIES OF TESTICULAR CANCER}

Several studies indicate an increased risk of testicular cancer in men with intellectual disability. The five epidemiological studies we have so far identified all suggest an increased risk of testicular cancer.

The issue was first addressed in a study conducted by the Irish Testicular Tumour Registry on all cases of testis cancer registered over the 1980-1985 period for a total of 240 cases. In this study, six patients were with intellectual disability, indicating a four-fold increased global risk $(\mathrm{p}<0.05)$ of developing testicular cancer for these men. The risk was increased 9-fold in patients with trisomy 21 (two cases in this study; $\mathrm{p}<0.05$ ) and by 4.5 in moderate to severe disabilities (four cases; $p<0.05$ ). It should be noted that no case was described for mild ID and some other conditions, thereby explaining why the overall risk is not in between the two specific risks presented above (8).

A more recent Finnish study was carried out on all cancer cases occurring in persons with ID both men and women by linkage of the data from the Population Register Centre of Finland with the Finnish cancer registry, following the identification of subjects with intellectual disability through a large population survey carried out on $9.4 \%$ of the entire population of Finland in 1962. Out of a total of 2,173 subjects, which included 1,090 men, still alive in 1967 and followed-up on until the end of 1997, revealed three testicular cancer cases, which correspond to a similar 4-fold increased risk (standardised incidence ratio (SIR) at 4.4, $95 \%$ Confidence Interval (CI): 0.8-10.8). In this study, the risk was higher for patients with severe disabilities (SIR: 9.9, CI: 1.235.6) as compared to those with slight or moderate disabilities (SIR: 2.1, CI: $0.1-11.6)(5)$.

One paper (9) examined the mortality from cancer in Denmark and Sweden based on a cohort of 4,872 individuals with a hospital discharge diagnosis of Down syndrome. Risk of testicular cancer was elevated (SIR: 3.7, CI; 1.0-9.4) with results similar in both countries in terms of incidence (SIR: 3.4, CI: 0.3-133.3 for Sweden and 26.4, CI: 0.3-146.6 for Denmark) and mortality (SMR: 24.0, CI: $0.3-133.3$ for Sweden and 26.4, CI:0.3-146.6 for Denmark) (9).

A third study from a cancer register in Australia reported (6) seven testicular cancer cases over a follow-up period of 20 years (1982-2001) among 9,409 persons registered with the Disability Services Commission of Western Australia, including 5,490 men with ID. The risk was slightly increased with a SIR at $1.43(0.58-2.95)$ compared to the general population (6).

An early British case-referent study of testicular cancer carried out between 1977 and 1981, reported 10 testicular cancer cases in persons with ID ( $3.9 \%$ of the cases), including two patients with trisomy 21 ( $0.8 \%$ of cases), out 
of a total of 259 cases (10). The risk was not estimated for the intellectually disabled men, but the reported figures are in favour of an increased risk of testicular cancer in this population.

The most recently published study (11) is a large population based cohort study of children with birth defects conducted in Norway and Sweden. The linkage of the national birth and cancer registries identified respectively 32 cases in Norway and 27 in Sweden yielding SIRs of 1.5 (1.0-2.1) and 1.9 (1.32.8). Specific results were given for the Down syndrome population. In Norway, five cases were observed for a SIR of 5.5 (1.8-13); in Sweden two cases were observed, but the SIR (which was stated to be not statistical significant) was not presented (11).

All these publications indicate an increased risk of testicular cancer in men with ID in general and not just restricted to patients with trisomy 21 . Further epidemiological studies are required to better estimate the risk globally, as well as for sub-groups by type, origin and severity of intellectual deficiency, and also to identify potentially specific risk factors in this population.

\section{SYNDROMES ASSOCIATED WITH AN EXCESS RISK OF TESTICULAR CANCER \\ Down syndrome}

Following the first publication of a case of testicular cancer in a patient with trisomy 21 (12), all studies have reported a higher frequency of germ-cell tumours in this population. The risk was estimated between 1.86 (13) and 50 $(14,15)$. Registry focused studies, which are of greater validity than other types of reports, gave results around 1.5 to 5 for the overall risk of testicular cancer, without specification of histological type. So far, we have collected 107 published cases and have found: 1) a higher proportion of seminomas ( $80 \%$ as compared with $40 \%$ in the general population), 2) a higher frequency of bilateral cases ( $8 \%$ as compared with $4 \%$ in the general population) and that 3 ) diagnosis is made at an earlier mean age (32 years as compared with 37 years in the general population) (1). Two rare cases of seminoma have also been reported before puberty (16). Among men with Down syndrome, tumours are more often discovered at an advanced stage ( $40 \%$ at stage 2 or beyond as compared with $10 \%$ in the general population), and even more so for tumours developing on ectopic intra-abdominal testis (17). A recent British study reported a higher frequency of disease recurrence following conventional therapy or modified treatment in order to adapt to cardiovascular, respiratory and kidney comorbidities frequent in these patients (18). Down syndrome, is undoubtedly associated with an increased risk of testicular cancer, but that association cannot by itself explain the global higher risk of testicular cancer for the whole population of the intellectually disabled. Other affections and syndromes also contribute to this increased risk.

\section{WAGR syndrome and aniridia}

A constitutional interstitial deletion on the short arm of chromosome 11 (11p13) leads to the WAGR syndrome (Wilms' tumour, aniridia, genitourinary malformations and mental retardation) whether with a complete or partial expression. At least five young boys with this condition have developed gonadoblastoma (19-22). These tumours occurred earlier in life than usual, diagnosed between the ages of 20 to 36 months in four children. This finding is important if one bears in mind that for about one patient out of two, the gonadoblastoma will eventually evolve into a malignant germ cell tumour, notably seminoma (23). Finally, an infant with ID and aniridia developed a 
paratesticular rhabdomyosarcoma and a myeloid leukemia at the age of 17 months, and eventually a Wilms' tumour and a neuroblastoma discovered at autopsy at 24 months of age (24).

\section{Proteus synd rome}

Proteus syndrome is a rare affection of unknown aetiology, where affected subjects develop numerous asymmetric and outsized tissue outgrowths as well as various tumours. Intellectual disability was observed in $30 \%$ of these subjects (25). In this condition, four patients developed cancer of the testis and its adnexa and a fifth subject experienced an intrascrotal extension of an abdominal tumour (26). In two children with mild ID, a para-testicular papillary adenoma was diagnosed at the age of 14 years in one of them (27, case 1), while the other child developed a well-differentiated malignant papillary mesothelioma of the tunica vaginalis at the age of $41 / 2$ years (28).

\section{Cowden syndrome}

Patients with Cowden syndrome, or multiple hamartomas syndrome, have an increased risk of developing cancers of the breast, thyroid, endometrium and skin. About $12 \%$ of them also expressed intellectual deficiency (29). This syndrome is often associated with testis lipomatosis, which rarely leads to deformity of the testis and easily identifiable on ultrasound scans $(30,31)$. It is a benign multifocal lesion, readily distinguishable from microlithiases on ultrasound scan. It usually appears around the age of 20 years, but its significance is not well apprehended. It is currently admitted that no particular treatment is recommended, so that further invasive exploration procedures should be avoided, when such typical ultrasound images are identified.

\section{Other genetic conditions}

Various histological types of tumours of the testis and its adnexa have been reported during childhood and adulthood in patients with rare to very rare genetic syndromes, which are often associated with intellectual disability. Examples include Smith-Lemli-Opitz syndrome (32), Rubinstein-Taybi syndrome $(33,34)$, Prader-Willi syndrome $(35,36)$, Sotos syndrome (37), Primerose syndrome (38) and Simpson-Golabi-Behmel syndrome (39). This can also be the case for the severe form of a syndrome predisposing to an excess risk of cancer and associated with ID, such as Gardner syndrome (40). Sometimes the genetic syndrome was not specifically mentioned $(14,41)$.

Conversely, in other genetic conditions associated with ID, testicular cancer seemed to be less common than in the general population. For instance, only two germ cell testicular tumours have been reported in men with the fragile-X syndrome in spite of the high frequency of this genetic condition (42, Ruvalca cited by 43). Similarly, only three intra-scrotal tumours have been reported in patients with tuberous sclerosis (44-46). In the case of Noonan syndrome, which is even more frequent, only two tumours have been reported, including one person with a normal intellect $(47,48)$. Also, two epidemiological studies have reported a decreased risk of testicular cancer for males with Klinefelter syndrome $(49,50)$. This has also been seen for Leydig cell tumours (51), which rarely occur in association with intellectual deficiency. Finally, only one testicular tumour was reported in an intellectually-deficient patient with neurofibromatosis (52).

\section{DISCUSSION}


Testicular cancer is rare in the general population, accounting for $1 \%$ of all malignant tumours, but affecting mainly young adults between the ages of 15 to 35 years. The standardised age world incidence rate is between 0.1 and 10.3 new cases per 100,000 male years (53). The epidemiological studies we summarized in our paper all indicated a higher risk for males with intellectual disability as compared to the general population. Yet a wide variation exists depending on the syndrome considered. The risk may even be lower than the general population for some conditions. Furthermore, we have no specific data concerning the frequency of testicular cancer in patients with non-geneticallylinked intellectual disability. The review of published articles revealed a different distribution of histological types as compared to the general population, where germ cell tumours (seminoma, embryonic carcinoma, teratoma, teratocarcinoma, yolk sac tumours and choriocarcinoma) represented over $95 \%$ of all testicular cancers (54). Regarding intellectually-deficient patients, we have reported a number of cases of non germ-cell tumours, such as gonadoblastoma (WAGR syndrome and aniridia, Smith-Lemli-Opitz syndrome), stromal tumours (Rubinstein-Taybi syndrome) and para-testicular tumours (Proteus syndrome, tuberous sclerosis, aniridia). Finally, it should be noted that many patients developed their tumour early in life, including during childhood.

The etiology of testicular cancer is still not fully known. The best established risk factor, known since the beginning of the 19th century (55) is cryptorchidism, which can be defined as the presence of a testis above the external inguinal ring or even within the abdominal cavity, not palpable in a non-anesthetized patient. This condition is associated with a 5 to 10 -fold increased risk, but it only accounts for $10 \%$ of all testicular cancer cases (56). We also have increasing evidence that an excess risk of testicular cancer could be related to in utero exposure to maternal estrogens, hypofertility, raised blood FSH levels, and consumption of foods, such as dairy products and meat, coming from animal treated with growth promoters and other stimulating products having an hormonal effect $(56,57)$.

In some syndromes associated with intellectual deficiency, the genetic defect may represent an oncogenic risk for the male gonad. For instance, in Down syndrome, the ectopic testes, high blood levels of gonadostimulins, hyperexpression of triplicate genes in the testis, immaturity of the germ cell line are factors contributive to carcinogenesis $(15,58)$. Alterations on the WT1 gene in the WAGR syndrome lead to the development of embryonic tumours such as gonadoblastoma (22). In Rubinstein-Taybi syndrome, the abnormalities on the CBP gene are linked to neoplastic transformation in several organs (34). Proteus syndrome is linked with an increased risk of mesothelial tumours, including paratesticular tumours (25).

More generally, a large number of genetic defects are associated with cryptorchidism, but this condition is also observed in non-genetically related intellectual impairment, and in particular, cerebral palsy, resulting from perinatal insult, or epilepsy (59). The relation between intellectual disability and cryptorchidism is well established. In a study, $41 \%$ of patients, and in particular those suffering from severe cerebral damage, had a misplaced testis $(59,60)$. Moreover, testicular atrophy, which is more often observed in intellectuallyimpaired males (61), is regarded as a risk factor for testicular cancer. Finally, other factors could also account for the excess risk of germ cell testicular cancer in intellectually-disabled men. These include excess weight, insufficient physical activity, a diet rich in dairy products and meat, but poor in fruits and vegetables, as well as premature birth (56) 
In males with Down syndrome, the diagnosis of testicular cancer is often delayed compared with the general population. The tumours are larger and more often diagnosed at an advanced stage (1), although this is not always the case (18). In intellectually disabled patients, tumours at a regional and/or metastatic stage, have been diagnosed for example in patients with Noonan syndrome (47), neurofibromatosis (52), Klinefelter syndrome (62), Primerose syndrome (38) and Prader Willi syndrome (35).

Testicular cancers are often revealed as a painless nodule, a feeling of heaviness, a swelling of the scrotum, or a pain in the scrotum, the inguinal or abdominal regions. Intellectually-disabled patients, and especially those with severe forms of deficiency for whom the risk of cancer seems to be higher (5) have a lot of difficulty in describing pain or physical symptoms $(4,7,63)$. Such patients may also be reluctant to reveal their tumour through ignorance, ill-ateasiness, fear of cancer or emasculation (64).

For all these different reasons, it seems sensible to consider the group of intellectually-disabled males as a whole, as having an increased risk of testicular cancer. Therefore, the medical follow-up of males with ID should include a systematic examination of the external genitalia and in case of doubt, a complementary ultrasound scan of the testes.

In practice, any abnormal testicular nodule should be considered to be potentially malignant (64). Some authors recommend routine self-examination of the testes, although no study has ever demonstrated its benefit. When this is not feasible, a regular examination of the testes should be performed by a medical professional, provided that the trust of the patient is obtained, with regard paid to his intimacy and using a rigorously-codified procedure.

The frequent occurrence of cryptorchidism in intellectually-disabled patients (59) represents a further hindrance to the early detection of testicular tumours. It is thus recommended to descend the testes into the scrotum to allow for a proper clinical examination (55). An early diagnosis aims at reducing morbidity and mortality outcomes, since tumours discovered at an advanced stage will normally require heavier chemotherapeutic procedures, with side effects that must be taken into account. (64).

\section{ACKNOWLEDGMENTS}

Daniel Satgé was supported by a grant from the Fondation Jérôme Lejeune. This paper was based on some material previously published in French as part of a review of the literature in a paper presenting two original cases. It has been updated and presented with a different focus, including additional studies obtained through a systematic literature review.

\section{REFERENCES}

1. Satgé D, Culine S, Sasco AJ, Nishi M, Réthoré M-O. A proposal for testicular surveillance in Down syndrome. J Applied Res Intellecr Disabil 2006;19:274.

2. Evenhuis HM. Medical aspects of ageing in a population with intellectual disability: III. Mobility, internal conditions and cancer. J Intellect Disabil Res 1997;41:8-18.

3. Hogg J, Northfield J, Turnbull J. Cancer and people with learning disabilities: the evidence from published studies and experiences from cancer services. Kidderminster: BILD Publ, 2001.

4. Réthoré M-O. How to talk to children with trisomy 21. Int J Disabil Hum Dev 2006;5:333-6. 
5. Patja $\mathrm{K}$, Eero $\mathrm{P}$, Iivanainen $\mathrm{M}$. Cancer incidence among people with intellectual disability. J Intellect Disabil Res 2001;45:300-7.

6. Sullivan SG, Hussain R, Threlfall T, Bittles AH. The incidence of cancer in people with intellectual disabilities. Cancer Causes Control 2004; $15: 1021-5$

7. Satgé D, Sasco AJ, Azema B, Culine S. Cancers in persons with intellectual deficiency: current data. In: Mental Retardation Research Focus. New York: Nova Sci, 2007:47-84.

8. Thornhill JA, Conroy RM, Kelly DG, Walsh A, Fennelly JJ, Fitzpatrick JM. An evaluation of predisposing factors for testis cancer in Ireland. Eur Urol 1988;14:429-33

9. Hill DA, Gridley G, Cnattingius S, Mellemkjaer L, Linet M, Adami HO et al. Mortality and cancer incidence among individuals with Down syndrome. Arch Intern Med 2003;163:705-11.

10. Swerdlow AJ, Huttly SR, Smith PG. Testicular cancer and antecedent diseases. Br J Cancer 1987;55:97-103.

11. Bjørge T, Cnattingius S, Lie RT, Tretli S, Engeland A. Cancer risk in children with birth defects and in their families: a population based cohort study of 5.2 million children from Norway and Sweden. Cancer Epidemiol Biomarkers Prev 2008; 17:500-6.

12. Holland WW, Doll R, Carter CO. The mortality from leukaemia and other cancers among patients with Down's syndrome (mongols) and among their parents. Br J Cancer 1962;16:177-86.

13. Hasle $\mathrm{H}$, Clemmensen IH, Mikkelsen M. Risks of leukemia and solid tumours in individuals with Down's syndrome. Lancet 2000;355:165-9.

14. Mann JR, Pearson D, Barrett A, Raafat F, Barnes JM, Wallendszus KR. Results of the United Kingdom Children's Cancer Study Group's malignant germ cell tumor studies. Cancer 1989;63:1657-67.

15. Satgé D, Sasco AJ, Curé H, Leduc B, Sommelet D, Vekemans M. An excess of testicular germ cell tumors in Down's syndrome. Three cases report and review of the literature. Cancer 1997;80:929-935.

16. Dada R, Kumar R, Kucheria K. A 2-year-old baby with Downs syndrome, cryptorchidism and testicular tumour. Eur J Med Genet 2006; 49:265-8

17. Kamidono S, Takada K, Ishigami J, Furumoto M, Urano Y. Giant seminoma of undescended testis in Down syndrome. Urology $1985 ; 25: 637-40$

18. Hafeez S, Sharma RA, Huddart RA, Dearnaley DP, Horwich A. Challenges in treating patients with Down's syndrome and testicular cancer with chemotherapy and radiotherapy: The Royal Marsden experience. Clin Oncol (R Coll Radiol). 2007;19:135-42.

19. Dufier JL, Phug LH, Schmelck P, Fekete C, de Grouchy J, Turleau C, Haye C. Délétion intercalaire du bras court du chromosome 11: aniridie, glaucoma, retard stature-pondéral et mental, ambiguité sexuelle, gonadoblastome, déficit en catalase. Bull Soc Ophtalmol Fr 1981;81:747-9.

20. Martinez-Mora J, Audi L, Toran N, Isnard R, Castellvi A, Perez Iribarne M, Egozcue J. Ambiguous genitalia, gonadoblastoma, aniridia and mental retardation with deletion of chromosome 11. J Urol 1989;142:1298-300.

21. Stefan H, Semecký V. Aniridia, gonadoblastoma, Wilms' tumor and deletion 11p13. Acta Medica (Hradec Kralove) 1998;41:29-33. 
22. Fischbach BV, Trout KL, Lewis J, Luis CA, Sika M. WAGR syndrome: a clinical review of 54 cases. Pediatrics 2005;116:984-8.

23. Ulbright TM. Tumours containing both germ cell and sex cord / gonadal stromal elements. In: Eble JN, Sauter G, Epstein JI, Seslerhenn IA. Pathology and genetics of the urinary system and male genital organs. Lyon: IARC Press, 2004:259-60.

24. Valdes-Dapena M, Arey JB. Multiple (4) primary neoplasms in a child with aniridia. Am J Pathol 1971;62:22a.

25. Cohen MM Jr. Proteus syndrome: an update. Am J Med Genet C 2005;137:38-52.

26. Gordon PL, Wilroy RS, Lasater OE, Cohen MM Jr. Neoplasms in Proteus syndrome. Am J Med Genet 1995;57:74-8.

27. Hornstein L, Bove KE, Towbin RB. Linear nevi, hemihypertrophy, connective tissue hamartomas, and unusual neoplasms in children. $\mathrm{J}$ Pediatr 1987;110:404-8.

28. Malamitsi-Puchner A, Dimitriadis D, Bartsocas C, Wiedemann HR. Proteus syndrome: course of a severe case. Am J Med Genet 1990;35:283-5.

29. Hanssen AM, Fryns JP. Cowden syndrome. J Med Genet 1995;32:117-9.

30. Lindsay C, Boardman L, Farrell M. Testicular hamartomas in Cowden disease. J Clin Ultrasound 2003;31:481-3.

31. Woodhouse J, Ferguson MM. Multiple hyperechoic testicular lesions are a common finding on ultrasound in Cowden disease and represent lipomatosis of the testis. Br J Radiol 2006;79:801-3.

32. Gracia R, Nieto JA, Nistal M, Iturriaga R, Lledó G, Barrio R, Lama R. Aniridia associated with gonadoblastoma in Smith-Lemli-Opitz syndrome An Esp Pediatr 1976;9:19-24.

33. Siraganian PA, Rubinstein JH, Miller RW. Keloids and neoplasms in the Rubinstein-Taybi syndrome. Med Pediatr Oncol 1989;17:485-91.

34. Kurosawa K, Fukutani K, Masuno M, Kawame H, Ochiai Y. Gonadal sex cord stromal tumor in a patient with Rubinstein-Taybi syndrome. Pediatr Int 2002;44:330-2.

35. Robinson AC, Jones WG. Prader Willi syndrome and testicular tumour. Clin Oncol (R Coll Radiol) 1990;2:117.

36. Jaffray B, Moore L, Dickson AP. Prader-Willi syndrome and intratubular germ cell neoplasia. Med Pediatr Oncol 1999;32:73-4.

37. Muraishi O, Kumamaru T, Nozaki Y, Mori Y, Tokue A. Testicular yolk sac tumour in a patient with Sotos syndrome. BJU Int 1999;83:357-8.

38. Mathijssen IB, van Hasselt-van der Velde J, Hennekam RC. Testicular cancer in a patient with Primrose syndrome. Eur J Med Genet 2006;49:127-33

39. Lapunzina P, Badia I, Galoppo C, De Matteo E, Silberman P, Tello A, Grichener J, Hughes-Benzie R. A patient with Simpson-Golabi-Behmel syndrome and hepatocellular carcinoma. J Med Genet 1998;35:153-6.

40. Shimizu M, Watanabe K, Yamada M, Watanabe S, Wakahara T. [A case of Gardner's syndrome with bilateral epididymis tumors, nasal polyp, bone anomalies and mental deficiency (author's transl)] Nippon Naika Gakkai Zasshi 1975;64:1384-90.

41. Nakano A, Yoshida M, Harada T, Araki A, Pineda L, Iijima M, Sezer C, Zhou L, Maruyama R. Intratubular germ cell neoplasia of unclassified type occupying the whole testis accompanied by a small mature teratoma and metastatic choriocarcinoma and Sertoli cell-only tubules in the other testis. Pathol Int 2003;53:726-32. 
42. Phelan MC, Stevenson RE, Collins JL, Trent HE 3rd. Fragile $X$ syndrome and neoplasia. Am J Med Genet 1988;30:77-82.

43. Cunningham $M$, Dickerman JD. Fragile $X$ syndrome and acute lymphoblastic leukemia. Cancer 1988;62:2383-6.

44. Perez-Atayde AR, Nunez AE, Carroll WL, Murthy AS, Vaitukaitis JL, Watson DJ, Bauer SB, Kozakewich HP. Large-cell calcifying Sertoli cell tumor of the testis. An ultrastructural, immunocytochemical, and biochemical study. Cancer 1983;51:2287-92.

45. Miller DR, Patel K, Allen JC, Horten B. Neuroblastoma, tuberous sclerosis, and subependymal giant cell astrocytoma. Am J Pediatr Hematol Oncol 1983;5:213-8.

46. Martin RW 3rd, Rady P, Arany I, Tyring SK. Benign Leydig cell tumor of the testis associated with human papillomavirus type 33 presenting with the sign of Leser-Trélat. J Urol 1993;150:1246-50.

47. Sriram K, Thomas K, Barnes R. Noonan's syndrome. With carcinoma of undescended testis. Ill Med J 1987;171:294-6.

48. Aggarwal A, Krishnan J, Kwart A, Perry D. Noonan's syndrome and seminoma of undescended testicle. South Med J 2001;94:432-4.

49. Hasle H, Mellemgaard A, Nielsen J, Hansen J. Cancer incidence in men with Klinefelter syndrome. Br J Cancer 1995;71:416-20.

50. Swerdlow AJ, Schoemaker MJ, Higgins CD, Wright AF, Jacobs PA; UK Clinical Cytogenetics Group. Cancer incidence and mortality in men with Klinefelter syndrome: a cohort study. J Natl Cancer Inst 2005;97:1204-10.

51. Lardennois B, El Hansa A, Bernier F, Birembaut P, Caron J, Lemaire P. Klinefelter et leydigiomes. A propos d'une observation. J Urol (Paris) 1981;87:631-4.

52. Tommerup N, Warburg M, Gieselmann V, Hansen BR, Koch J, Petersen GB. Ring chromosome 22 and neurofibromatosis. Clin Genet 1992;42:171-7.

53. Parkin DN, Whelan SL, Ferlay J, Teppo L, Thomas DB. Testis. In: Cancer incidence in five continents, vol 8. Lyton: IARC Press, 2002: 636-8.

54. Huyghe E, Plante $\mathrm{P}$, Thonneau PF. Testicular cancer variations in time and space in Europe. Eur Urol 2007;51:621-8.

55. Giwercman A, Müller J, Skakkeboek NE. Cryptorchidism and testicular neoplasia. Horm Res 1988;30:157-63.

56. Garner MJ, Turner MC, Ghadirian P, Krewski D. Epidemiology of testicular cancer: an overview. Int J Cancer 2005;116:331-9.

57. Weir HK, Marrett LD, Kreiger N, Darlington GA, Sugar L. Pre-natal and peri-natal exposures and risk of testicular germ-cell cancer. Int $\mathbf{J}$ Cancer 2000;87:438-43.

58. Cools M, Honecker F, Stoop H, Veltman JD, de Krijger RR, Steyerberg $\mathrm{E}$, et al. Maturation delay of germ cells in fetuses with trisomy 21 results in increased risk for the development of testicular germ cell tumors. Hum Pathol 2006;37:101-11.

59. Cortada X, Kousseff BG. Cryptorchidism in mental retardation. J Urol 1984;131:674-6.

60. Fallon B, Welton M, Hawtrey C. Congenital anomalies associated with cryptorchidism. J Urol 1982;127:91-3.

61. Sylvester PE. The testes in the mentally handicapped. J Ment Defic Res $1973 ; 17: 52-7$. 
62. Soria JC, Durdux C, Chrétien Y, Sibony M, Damotte D, Housset M. Malignant Leydig cell tumor of the testis associated with Klinefelter's syndrome. Anticancer Res 1999;19:4491-4.

63. Hennequin M, Morin C, Feine JS. Pain expression and stimulus localisation in individuals with Down's syndrome. Lancet 2000;356:1882-7.

64. Moul JW. Timely diagnosis of testicular cancer. Urol Clin North Am 2007;34:109-17. 